\title{
Multi-Factor Analysis of External Effects Influencing the Operational Reliability of Asynchronous Electric Motors
}

\author{
Victoria Romanova ${ }^{1 *}$, Sergey Khromov ${ }^{1}$, Konstantin Suslov ${ }^{2}$ \\ ${ }^{1}$ Trans-Baikal State University, Department of Electric Power Generation and Electrical Engineering, Russia, Chita, 30, Aleksandro- \\ Zavodskaya Str. \\ ${ }^{2}$ Irkutsk National Research Technical University, Department of Power Supply and Electrical Engineering, Russia, Irkutsk, 83, \\ Lermontov Str.
}

\begin{abstract}
The paper considers the main issues of increasing the operational reliability of low-voltage asynchronous electric motors based on a set of studies performed using simulations in the Simulink Matlab software environment. The study defines the allowable operation of asynchronous electric motors under the influence of operational factors. We have conducted the analysis and discussion of the research results and suggested measures aiming to increase the operational reliability of asynchronous electric motors.
\end{abstract}

\section{Introduction}

The reliability of an electrical machine means its ability to reliably operate with unchanged technical parameters for a given period of time under certain modes and conditions of use, maintenance, storage, and transportation [1,2]. It should be noted that the performance and operational reliability of asynchronous electric motors (AM) depends not only on their design and manufacture quality, but also on their operating conditions. In real operation conditions of electric motors, depending on various factors, there is a significant deviation from the nominal operating conditions. Research and many years of operating experience [3-5] show that service life of electric motors is affected by climatic and electromechanical environmental factors; more than $50 \%$ of electric motors operate under conditions with parameters that are significantly different from the standardized ones as per the State Standards GOST R 51137-98 [6] and GOST IEC 60034 -1- 2014 [7].

The analysis of studies [8-10] in operability and operational quality of an AM in various modes of operation, under various external effects, shows that, during operation, the AM service life is greatly affected by the supply voltage quality (more than $60 \%$ of failures), vibration, temperature and humidity of the ambient air (more than $20 \%$ of failures), the electric motor loading. The above factors determine the AM operational reliability, but only in aggregate, as the failure statistics $[11,12]$ shows that electric motor failures are most often associated with several factors. That is why, when assessing operational reliability, we should take into account the combined effect of adverse factors, which will allow us to more accurately predict the real service life of electric motors, thereby providing the required level of AM reliability.

The main goal of our study is to systematize the AM operating conditions under a simultaneous influence of several operational factors.

The implementation of the suggested approach consists in a multi-factor analysis of the parameters of external factors affecting the electric motor load reliability. The concept of a system approach allows to address the problems of ensuring the safe and effective AM operation in a wide range of external factors.

\section{Materials and Research Methods}

The main goal of our study is quantitative evaluation of influencing factors in various operation modes of an AM with a squirrel-cage rotor using a virtual simulation implemented in a visually intuitive and efficient simulation tool - Simulink of the interactive programming environment Matlab, characterizing longterm AM operation.

The simulation diagram for studying the squirrel-cage AM operating modes, that has been generated using simulation tools in the Matlab/Simulink environment $[13,14]$, is shown in (Fig. 1).

The developed model allows to visually simulate the physical processes occurring in an AM, to study its performance and operational quality in various operation modes under various external effects. By changing the initial conditions and process parameters, we can observe changes in the AM simulation behavior of different series and capacities.

The research has been carried out on an asynchronous electric motor with a squirrel-cage rotor AIR160S8 with $\mathrm{Pn}=7.5 \mathrm{\kappa W}$ and a rated speed $\mathrm{n}=1500 \mathrm{rpm}$ [15].

\footnotetext{
*Corresponding author: romanova181@mail.ru
} 


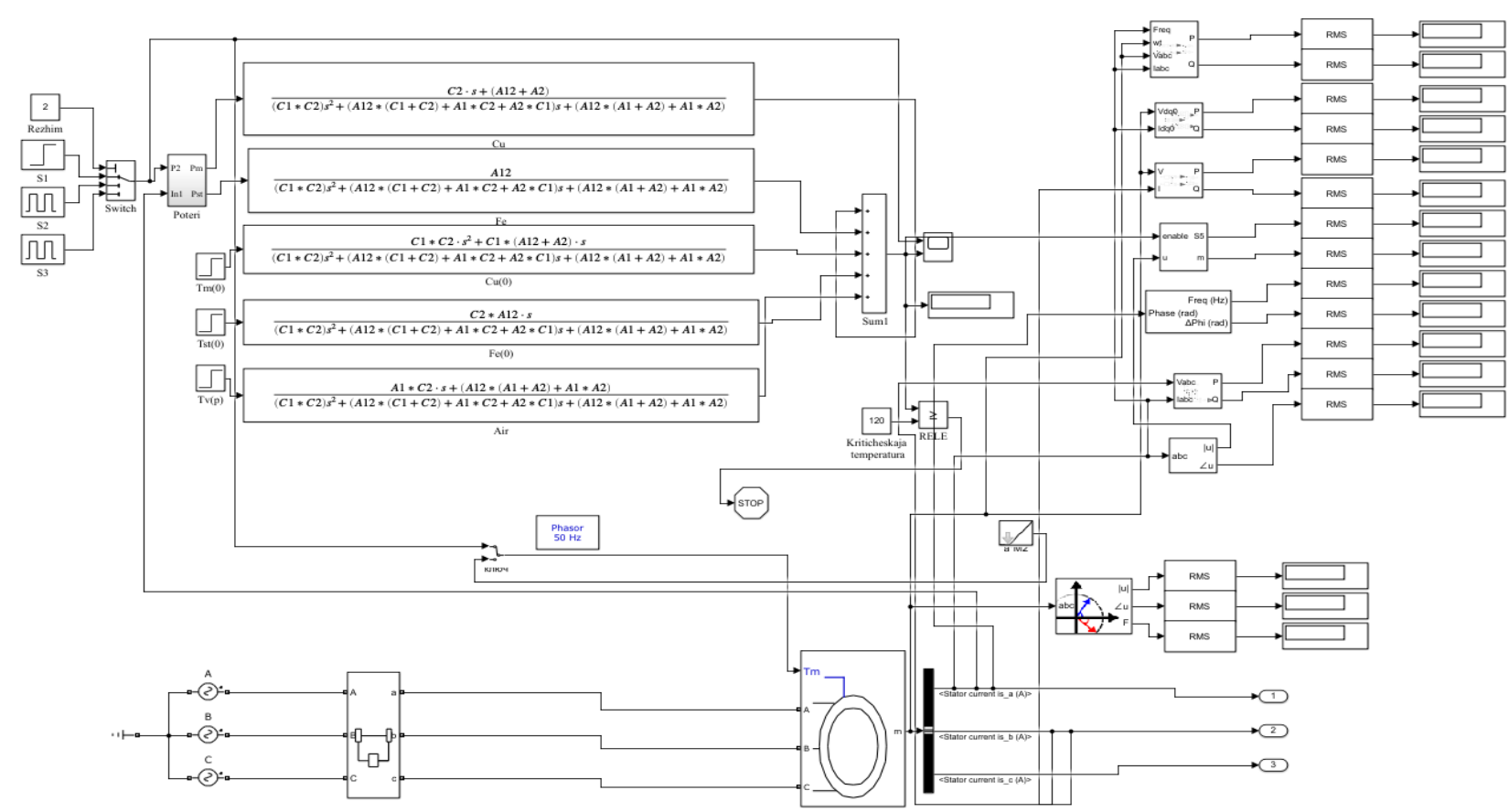

Fig.1. Simulation scheme implemented in Matlab/Simulink environment.

General industrial asynchronous electric motors AIR160S8 are manufactured for the following operating conditions:

- climatic version: $\mathrm{U}$

- installation category: 2, 3;

- operating mode: long-term, S1;

- permissible ambient temperature: $40^{\circ} \mathrm{C}$ to $-45^{\circ} \mathrm{C}$;

- insulation class: E, permissible AM winding temperature: $120^{\circ} \mathrm{C}$;

- protection level: IP54, 55 (the content of nonconductive dust in the air up to $100 \mathrm{mg} / \mathrm{cu} . \mathrm{m}$; the motor is protected from splashing water from any direction).

As a result of statistical analysis of the time diagrams of changes in the value of $\mathrm{K}_{2 \mathrm{U}}$, based on experimental studies of the electrical energy quality indicators (EQI) in $0.4 \mathrm{KV}$ distribution networks $[16,17]$, we established that the most probable values of the continuous voltage unbalance duration are the values within the range of 5 to 15 minutes.

Simulation of the physical processes of the AM under study has been carried out by changing the following parameters:

- the voltage unbalance factor in the reverse sequence $\left(\mathrm{K}_{2 \mathrm{U}}\right)$ - from 0 to $5 \%$ with a pitch of $1 \%$;

- the load on the motor shaft $\left(\mathrm{K}_{\mathrm{z}}\right)$ changed from 0 to $120 \%$ with a pitch of $20 \%$ at different values of $\mathrm{K}_{2 \mathrm{U}}$;

- the ambient temperature $\left(\mathrm{t}_{\mathrm{amb}}\right)$ changed from $40^{\circ} \mathrm{C}$ to $-40^{\circ} \mathrm{C}$ with a pitch of $10^{\circ} \mathrm{C}$;

- the voltage unbalance duration in reverse sequence (T) - from 0 to 15 minutes with a pitch of 5 minutes.

\section{Research Results and Their Discussion}

Using the developed computer simulation, we have obtained the data of comprehensive influence of functionally unrelated parameters, based on which we have built analytical dependencies (Figs. 2-5), describing the relationship of external factors that determine the AM operational reliability.

Based on the obtained computer simulation results, we have built groups of planes that allow to visually assess the limits of acceptable external factors values.

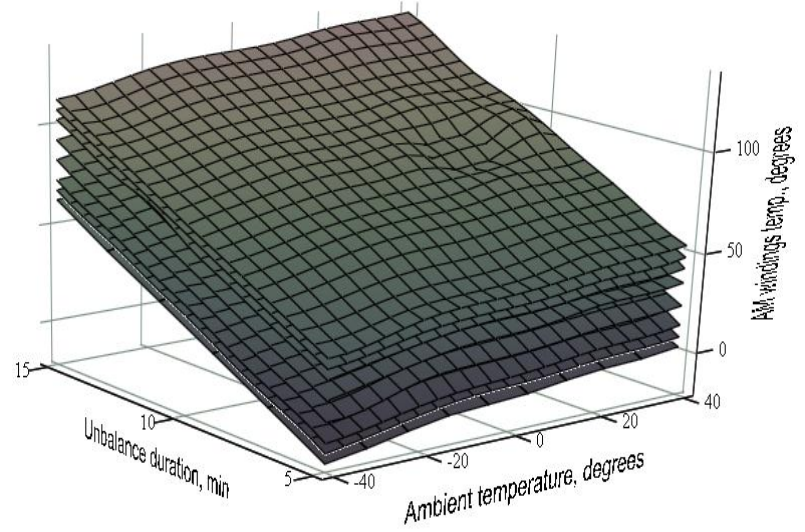

Fig. 2. Dependence of the AM windings temperature on external factors at various constant loading factors.

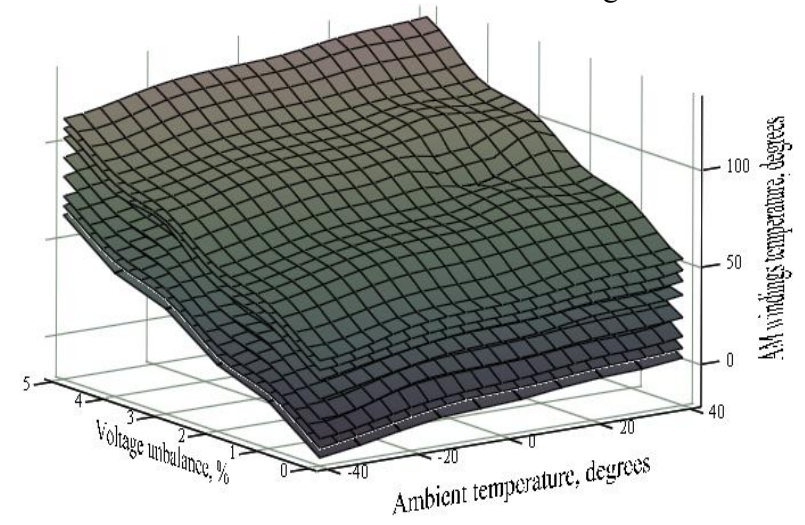

Fig. 3. Dependence of the AM windings temperature on external factors at various constant loading factors. 


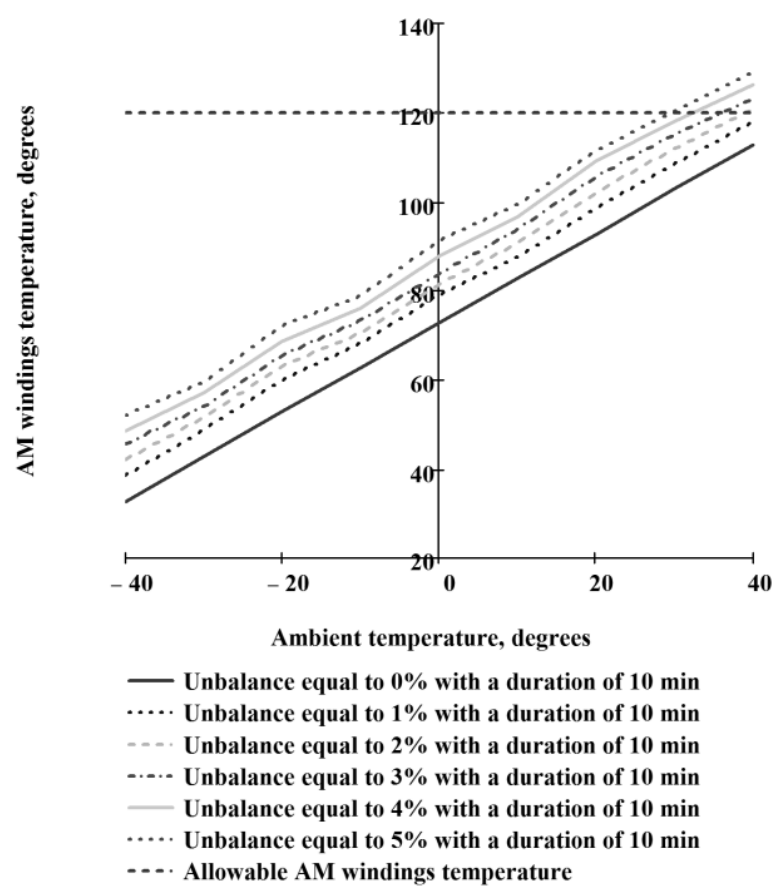

Fig. 4. Dependence of the ambient temperature on the AM windings temperature at $\mathrm{K}_{2 \mathrm{U}}=0-5 \%$ with a constant value of the voltage unbalance duration.

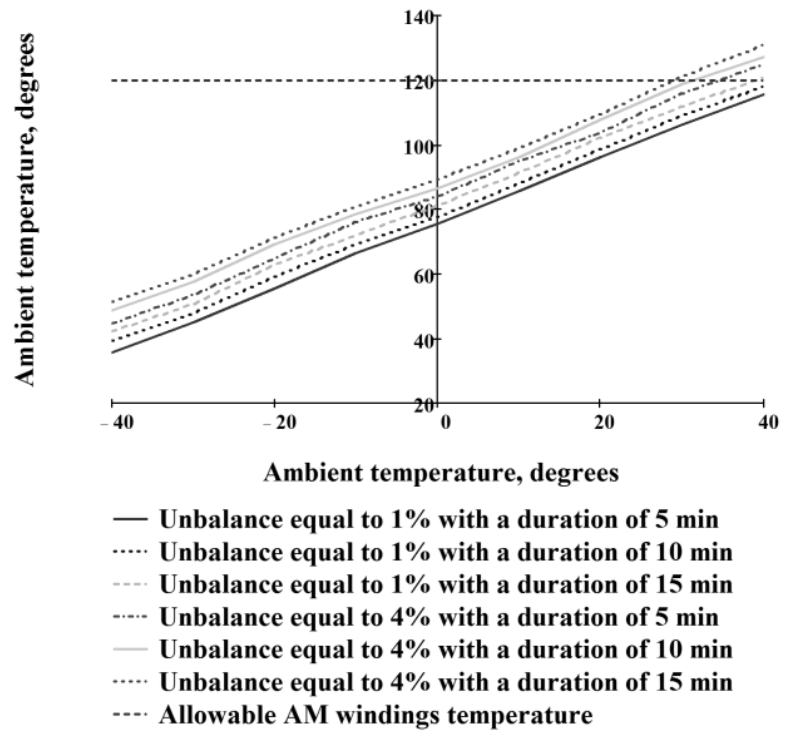

Fig. 5. Dependence of the ambient temperature on the AM windings temperature $\mathrm{K}_{2 \mathrm{U}}=1 \% ; \mathrm{K}_{2 \mathrm{U}}=4 \%$ with various unbalance duration.

Summarizing the experimental material has revealed the following patterns:

1) the operational reliability is influenced not only by external factors that are directly related to the AM operation (voltage unbalance, AM loading), but also by climatic factors (ambient temperature). Thus, at $\mathrm{t}_{\mathrm{amb}}=$ $30{ }^{\circ} \mathrm{C}, \mathrm{K}_{2 \mathrm{U}}=4 \%$, and $\mathrm{T}=10 \mathrm{~min}$., the $\mathrm{AM}$ windings temperature exceeds the permissible operating temperature of the electric motor; whereas under the same conditions, but at $\mathrm{t}_{\mathrm{amb}}=20^{\circ} \mathrm{C}$, the $\mathrm{AM}$ windings temperature does not reach the permissible operating temperature of the electric motor;

2) the voltage unbalance duration significantly contributes to the cumulative negative effect of all factors. E.g., at $\mathrm{K}_{2 \mathrm{U}}=1 \%$ and $\mathrm{t}_{\mathrm{amb}}=37^{\circ} \mathrm{C}$, at $\mathrm{T}=5 \mathrm{~min}$., the $\mathrm{AM}$ windings temperature is $115^{\circ} \mathrm{C}$; whereas under the same conditions, but at $\mathrm{T}=10 \mathrm{~min}$., the $\mathrm{AM}$ windings temperature is $118^{\circ} \mathrm{C}$; at $\mathrm{T}=15 \mathrm{~min}$., the $\mathrm{AM}$ windings temperature is $122^{\circ} \mathrm{C}$;

3) the AM loading is a factor in the operational reliability of electric motors. E.g., at $\mathrm{K}_{\mathrm{z}}=100 \%, \mathrm{~K}_{2 \mathrm{U}}=$ $1 \%, \mathrm{~T}=10 \mathrm{~min}$., at $\mathrm{t}_{\mathrm{amb}}=40^{\circ} \mathrm{C}$, a stable operation of the electric motor will be provided. Upon exceeding the AM loading value $\mathrm{K}_{\mathrm{z}}=100 \%$, we need to adjust one of these factors, taking into account the real operating conditions;

4) a significant decrease in AM reliability occurs at $\mathrm{K}_{2 \mathrm{U}}$ exceeding $4 \%$. To prevent overheating and premature failure of the AM, we need to change one or more of the factors under study. E.g. at $\mathrm{K}_{2 \mathrm{U}}=3 \%, \mathrm{~T}=10 \mathrm{~min}$., $\mathrm{t}_{\mathrm{amb}}=$ $34^{\circ} \mathrm{C}, \mathrm{K}_{\mathrm{z}}=88 \%$, the $\mathrm{AM}$ windings insulation starts to overheat; therefore, we should reduce AM loading by at least $10 \%$;

5) it is advisable to show the influence of several factors on the operational reliability of AMs by ranking these factors according to their contribution (weight) value. Using the Steinhaus-Ford-Johnson algorithm [18], we obtained the following ranking in descending order of contribution: the greatest influence of the investigated factors is exerted by the voltage unbalance; the next factor is AM loading; then, the voltage unbalance duration; and the least influence is due to the ambient temperature. The ranking of factors is based on the AM windings temperature range depending on the influence of the factors under study.

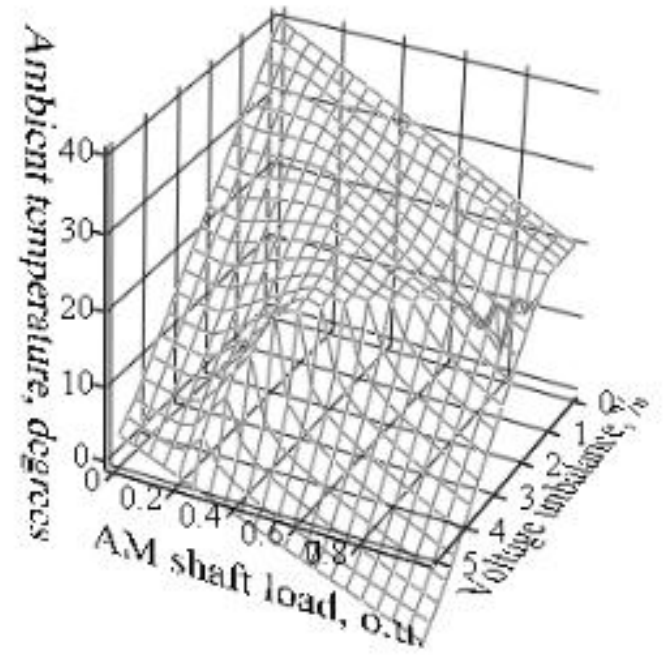

Fig. 6. Range of admissible values of the factors under study.

The graphical dependence plotted in (Fig. 6) describes the set of possible AM operation modes with various values of external factors. The plane shown in the graph illustrates a set of boundary points of acceptable AM operation, such as $\mathrm{K}_{\mathrm{z}}=100 \%, \mathrm{~K}_{2 \mathrm{U}}=5 \%, \mathrm{t}_{\mathrm{amb}}=40^{\circ} \mathrm{C}$. The optimal AM operating mode at various values of external factors is one of the points of the plane, e.g., at $\mathrm{t}_{\mathrm{amb}}=30^{\circ} \mathrm{C}$ and $\mathrm{t}_{\mathrm{amb}}=40^{\circ} \mathrm{C}$, the optimal AM operating mode will be individual. Despite the fact that the range of permissible values is theoretically large, under real AM operating conditions, it will be significantly reduced depending on the specifics of the process involving an electric motor. 
Therefore, based on a set of studies performed using simulations in the Simulink Matlab software environment, we have formulated the main conclusions:

1) the effect of unfavorable factors significantly reduces the reliability of asynchronous electric motors;

2) our research shows the need for a small underloading of AMs in the design and operation of facilities involving an electric motor load, to create a damper for neutralizing the negative effects of external factors;

3) the corridor of temperature fluctuations of windings, with a change in the voltage unbalance and (or) in its duration, reaches $20^{\circ} \mathrm{C}$, which means that, even with an AM underload, measures should be provided to reduce the voltage unbalance, if facilities are located in the influence area of a powerful and sharply variable unbalanced load;

4) the experimental research has shown that the combined effect of external factors significantly exceeds that of one factor;

5) the quantitative analysis of external influencing factors plays a key role in the implementation of engineering solutions (means and methods), aimed at increasing the reliability of asynchronous electric motors.

The systematization of the AM operating conditions with the simultaneous influence of a group of operational factors shows that, to ensure reliable operation of electric motors, simultaneous excess of the following factors shall be avoided: $\mathrm{K}_{\mathrm{z}}=100 \%, \mathrm{t}_{\mathrm{amb}}=40^{\circ} \mathrm{C}, \mathrm{K}_{2 \mathrm{U}}=4 \%$, at $\mathrm{T}=10$ min. A short-term excess of one of these factors by $20 \%$ of the critical value is allowed.

\section{Conclusion}

The efficient use of electrical machines is largely dependent on their operational reliability. That is why the analysis of the operational factors impact on the AM reliability, which is a quantitative assessment of the parameters of external effects, allows to assess the actual contribution of each of these parameters, to determine the permissible operation range of asynchronous electric motors, and, additionally, to develop engineering solutions that ensure long-term operation of electric motors with the maximum probability of their trouble-free operation.

\section{References}

1. O. Goldberg, The reliability of electrical machines. M.: Publishing Center «Academy», 288 (2010).

2. N. Kuznetsov, Reliability of electric machines. M.: Publishing house MEI, 432 (2006).

3. V. Kozhukhov, S. Strizhnev, Review of technological failures of asynchronous motors in agricultural production. K.: Publishing house of KrasGAU, №. 11, 199 - 202 (2006).

4. V. Field, M. Ezhova, Influence of operational factors on the reliability indicators of asynchronous motors. Publishing house of TulSU, Issue. 9, Part 1, 143 147 (2013).

5. A. Gusarov, Influence of the quality of electrical energy on the thermal state of three-phase asynchronous motors with a squirrel-cage rotor. DonNTU, № 8 (140), 95 - 97 (2008).

6. GOST R 51137 - 98. Adjustable asynchronous electric drives for power facilities. General technical conditions. M.: IPK Publishing house of standards, 15 (1998).

7. GOST IEC $60034-1$ - 2014. Rotating electrical machines. Part 1. Ratings and performance characteristics. M.: Standartinform, 62 (2015).

8. V. Romanova, S. Khromov, Operational reliability of low-voltage asynchronous electric motors in conditions of voltage asymmetry. T.: Publishing house of Tashkent State Technical University, №4, $136-148$ (2019).

9. S. Khomutov, Analysis of the influence of external influencing factors on the state of insulation of electric motors. B.: Publishing Center AltGTU im. I.I. Polzunova, № 4, Part 3, 260 - 267 (2005).

10. O. Pinchuk, Assessment of the thermal state of asynchronous motors in intermittently intermittent modes with unbalanced network voltage. Vestnik SevDTU, Issue. 88, 97 - 103 (2008).

11. M. Fedorov, Features of the thermal state of asynchronous motors with an asymmetric supply voltage. K.: Publishing Bulletin of the Kremenchug state Polytechnic University, Vol. 2 (25), 122 - 125 (2004).

12. S. Khomutov, E. Kobozev, Forecasting the probability of failure-free operation of electric motors on the basis of a quantitative assessment of the degree of influence of influencing factors. B.: Publishing Center AltSTU im. I.I. Polzunova, № 2, $4-8$ (2006).

13. S. German-Galkin, G. Kardonov, Electrical machines: Laboratory works with PC. SBR: Koronaprint, 256 (2003).

14. I. Chernykh, Simulation of electrical devices using MATLAB, SimPowerSystems and Simulink. SBR: Piter M.: DMK Press, 288 (2008).

15. http://electronpo.ru/dvigatel_air160s

16. A. Ded, On the problem of the current state of the levels of unbalance indicators of voltages and currents in $0.4 \mathrm{kV}$ networks. O.: Publishing house of OmSTU, 63 - 65 (2017).

17. Protocol № 5. Claim tests of electrical energy in terms of quality indicators, 27 (2013).

18. E. Klyushnikova, E. Shitova, Methodological approaches to calculating the integral indicator, methods of ranking. T.: Publishing house of the Tverskoy InnoCenter, №1(10), 4 - 18 (2016). 